\title{
COMPORTAMIENTO TEMPORAL DEL PLANCTON ANTE FACTORES OCEANOGRÁFICOS EN LAS ESTACIONES DE ESMERALDAS, PUERTO LÓPEZ Y SALINAS *
}

\section{TEMPORARY BEHAVIOR OF PLANCTON BEFORE OCEANOGRAPHIC FACTORS IN THE STATIONS OF ESMERALDAS, PUERTO LÓPEZ AND SALINAS*}

\author{
Robert Bucheli $^{1}$ \\ Universidad de Guayaquil, Facultad de Ciencias Naturales ${ }^{2} 1$ Instituto Nacional de Pesca (INP), \\ *Universidad de Guayaquil (UG), Maestría, Facultad de Ciencias Naturales. \\ E-mail: rbucheli@institutopesca.gob.ec
}

\begin{abstract}
RESUMEN
Se determinó el efecto de los componentes oceanográficos en la abundancia, diversidad, riqueza de especies de plancton en aguas superficiales, a diez millas frente a la costa de Esmeraldas, Puerto López y Salinas. El periodo de estudio fue 2004 - 2012 y en el procesamiento de datos se aplicó análisis de componentes principales y correspondencia canónica. Se detectó variación latitudinal significativa $(P<0.05)$, de la temperatura superficial del mar, silicatos, nitratos, fitoplancton y zooplancton, observándose en los dos primeros, un gradiente de descenso de norte a sur, y en los tres últimos de sur a norte. Los restos de variables no mostraron diferencia alguna. La temperatura influyo muy poco en el fitoplancton, pero fue importante para el zooplancton. Los nutrientes estuvieron disponibles en los rangos para el desarrollo del fitoplancton. Respecto a las interrelaciones entre variables, se observó a Nitzschia longissima y Cylindrotheca closterium asociadas al nitrato y silicato (Puerto López y Salinas), Hemiaulus hauckii a la temperatura (Esmeraldas y Puerto López) y Oncaea. cleveis al oxígeno disuelto (Puerto López y Salinas). La dinámica temporal del plancton muestra estar ligada a las variaciones de temperatura y concentraciones de nutrientes.
\end{abstract}

Palabras claves: diversidad, fitoplancton, variabilidad, zooplancton.

\begin{abstract}
The effect of the oceanographic components on the abundance, diversity and richness of plankton species in surface waters was determined, ten miles off the coast of Esmeraldas, Puerto López and Salinas. The period of study was 2004 - 2012 and in the processing of data, analysis of principal components and canonical correspondence was applied. Significant latitudinal variation $(P<0.05)$, sea surface temperature, silicates, nitrates, phytoplankton and zooplankton were detected, observing in the first two, a gradient of descent from north to south, and in the last three from south to north. The remains of variables showed no difference. The temperature influenced the phytoplankton very little, but it was important for the zooplankton. Nutrients were available in the ranges for phytoplankton development. Regarding the interrelations between variables, Nitzschia longissima and Cylindrotheca closterium were found to be associated with nitrate and silicate (Puerto López and Salinas), Hemiaulus hauckii at temperature (Esmeraldas and Puerto López) and Oncaea. cleveis at dissolved oxygen (Puerto López and Salinas). The temporal dynamics of the plankton show to be linked to the variations of temperature and nutrient concentrations.
\end{abstract}

Keywords: diversity phytoplankton, variability, zooplankton. 


\section{INTRODUCCIÓN}

Las capas superficiales del pacifico oriental frente a las costas de Ecuador están sometidas a variaciones físicas y químicas estacionales, causadas por dos grandes ecosistemas marinos: el del Pacífico Central $y$ el de la corriente de Humboldt, ecosistemas que han originado en la zona norte y parte de la central características de tipo tropical con predominio de aguas cálidas resultantes de la corriente de Panamá cuya temperatura varía entre 23 y $27{ }^{\circ} \mathrm{C}$ (Comisión Permanente del Pacífico Sur (CCPS), 2014), mientras la zona sur está influenciada por aguas de características frías entre 20 y $25{ }^{\circ} \mathrm{C}$, proveniente de un ramal de la corriente de Humboldt (CPPS, 2014).

El encuentro de las dos corrientes crea una zona de transición debido a la mezcla de aguas de diferentes temperaturas, ocasionando oscilaciones térmicas y desalojo de las masas de agua, según la estación que esté presente durante el año. De diciembre a abril se produce la época húmeda (invierno) y de mayo a noviembre la temporada seca (verano) (Cruz, 2012).

En las aguas cálidas de la zona norte y parte de la central, se desarrolla una alta biodiversidad y bajas biomasas, mientras en las aguas frías del sur, reflejan alta biomasa y baja diversidad (Flores et al., 2013).

Cabe destacar, que los patrones de circulación local asociados con los parámetros físicos varían la posición espacial de los organismos. Una variable física de gran importancia en el ecosistema marino es la temperatura superficial del mar (TSM): Factor que ejerce un impacto importante en las comunidades en una localidad determinada (Ayala et al., 2016).
Al variar, durante el intervalo del día, en unos grados centígrados influye marcadamente en la distribución de los organismos del plancton, ya que las diversas actividades normales se desarrollan bien en determinados límites térmicos (Cognetti et al., 2001), y de la tolerancia fisiológica a temperaturas altas (Mesas \& Tarifeño, 2015).

Así mismo, la salinidad, tiene trascendental importancia en las actividades biológicas. En el mar el valor de la salinidad están asociadas a las diferentes masas de aguas. Las capas superficiales del mar son ocupadas por Aguas Ecuatoriales Superficiales (AES) y ATS de bajas salinidades y por ACF de altas salinidades (Dioses, 2013), bajos las diferentes condiciones de temperatura y salinidad, las especies planctónicas se distribuyen de acuerdo al grado de tolerancia en la cual pueden sobrevivir.

Por otro lado, el movimiento de las aguas subsuperficiales llevan aguas frías ricas en nutrientes hacia la capa de mezcla motivando los florecimientos, que enriquece al medio marino, propiciando la proliferación de consumidores secundarios y terciarios. Sin embargo, los nutrientes como el nitrógeno $(\mathrm{N})$, fósforo $(\mathrm{P})$ y silicio $(\mathrm{Si})$, que regulan el crecimiento del fitoplancton, pueden ser factores limitantes, por su insuficiente concentración en el mar (Gadea Pérez, 2012).

Considerando las condiciones oceanográficas mencionadas, se han realizado estudios del plancton marino, evidenciándose la influencia que ejercen los parámetros abióticos y bióticos sobre el plancton.

De la Cuadra (2009), analizo la información oceanográfica y meteorológica, en tres estaciones localizadas a 10 millas fuera de la 
costa del Ecuador durante el periodo 20042008.

Calderón y Lindao (2009), Observaron un descenso en la densidad y variedad de especies ictioplanctónicas en el 2008 con respecto al 2006 y 2007. Cruz et al. (20102011), Investigaron el evento El Niño 20092010 de las regiones Niño 1+2 y 3.4, y determinaron que una de las la especie más frecuente durante el evento fue Hyalocylis striata.

Gualancañay et al. (2010-2011), que caracterizaron la bahía de Jaramijó, observaron mayor cantidad de fitoplancton y zooplancton en época lluviosa que en la época seca.

Tapia y Naranjo (2012), relacionaron los Aspectos oceanográficos del plancton con el frente ecuatorial, concluyendo que: Thalassiosira subtilis, Chaetoceros curvisetus Ch. eibenii, Rhizosolenia imbricata, Proboscia alata y Planktoniella sol fueron las especies más abundante a lo largo del frente. Cruz (2012), analizó los rangos de tolerancia a la temperatura, salinidad y reacción con el tipo de masas aguas, de 14 especies de gasterópodos planctónicos dando a conocer las preferencias ecológicas de cada especie.

Tapia (2013), examino los efectos de la prospección sísmica en la composición y distribución del fitoplancton, registrando mayor dominancia de diatomeas y menor concentración de dinoflagelados, cocolitofóridos, silicoflagelados, cianobacterias y tintinnidos.

Belén et al. (2013), realizó un análisis de 30 años del comportamiento climático en tres estaciones en las costas ecuatorianas en época húmeda, observando una tendencia hacia el aumento de la temperatura superficial del aire y del mar, y un comportamiento diferente de las precipitaciones a lo largo del tiempo.

Luzuriaga (2015), comparo la distribución y relaciones ecológicas de los foraminíferos planctónicos en condiciones normales y durante el niño 1997-1998, tipifico a Globigerinoides sacculifer como una de las especies que predominó en el evento el Niño 1997 -1998, en su etapa madura.

Esta investigación realiza un análisis histórico de la abundancia, distribución de fitoplancton y zooplancton y su relación con algunas variables ambientales en las estaciones de Esmeraldas, Puerto López y Salinas, para determinar las reacciones del plancton, ante cambios de temperatura $\mathrm{y}$ densidad de los nutrientes.

\section{MATERIALES Y MÉTODOS}

La información para realizar este trabajo fue obtenida de las bases de datos de los departamentos de plancton, de química $\mathrm{y}$ física del proyecto Variabilidad Climática ejecutado por el Instituto Nacional de Pesca, en estaciones ubicadas a 10 millas del margen costero de las provincias de Esmeraldas $\left(79^{\circ} 46^{\prime} 498 . \quad \mathrm{O} ; 1^{\circ} 7^{\prime} 42.2 . \mathrm{N}\right)$, Puerto López (Manabí) (8102'217. O; $1^{\circ} 34^{\prime} 9.6$. S) y Salinas (Santa Elena) (81 ${ }^{\circ} 06 ' 18.6$. O; 2॰12'3.36. S) (figura 1) entre los años 2003 a 2012 con una frecuencia de muestreo mensual. 


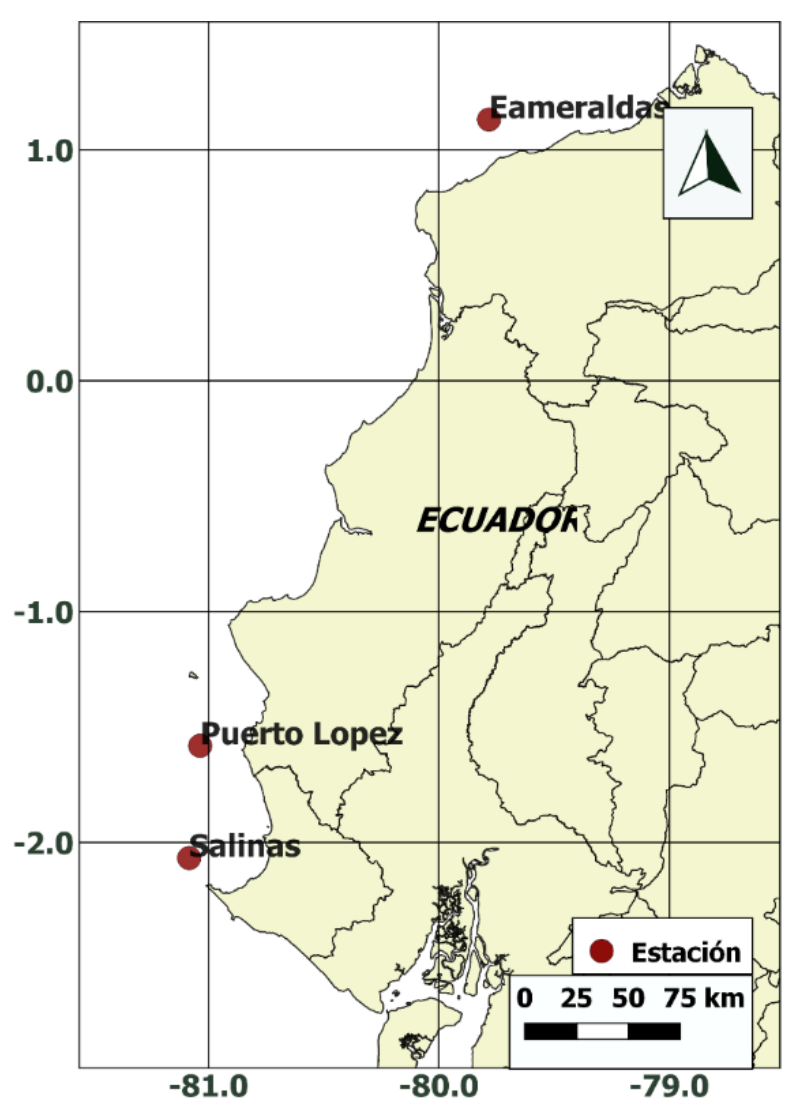

Figura 1. Ubicación de las estaciones de estudio a 10 millas frente al perfil costero de Ecuador.

Figure 1. Location of study stations 10 miles away from the coastal profile of Ecuador.

Se utilizaron embarcaciones de fibra de vidrio propulsada por un motor fuera de borda y mediante un GPS (Global Position System) se ubicó el punto de muestreo.

Se tomaron datos de temperatura superficial del mar (TSM) mediante un termómetro de mercurio, el cual fue sumergido en un balde con agua de mar durante cinco a diez minutos; registrando la temperatura en una bitácora. Luego se sumergió un disco de Secchi, midiendo la profundidad de transparencia del agua.

Se colectaron muestras de agua para oxígeno disuelto (Carpenter, 1965), nutrientes como nitrito, nitrato, fosfato $\mathrm{y}$ silicatos (Parsons et al. (1984) y fitoplancton (Ferrario et al., 1995) mediante la sumersión de una botella Niskin a 0, 10, 30, 50, 75 y
$100 \mathrm{~m}$ de profundidad. Después a bordo, se procedía a la colecta de agua, en botellas de polietileno de $500 \mathrm{ml}$ de capacidad. Posteriormente el líquido para determinar oxígeno disuelto era filtrado al vacío por medio de membranas de filamentos de vidrio Wathman GF/C. Los filtros eran colocados en papel aluminio e inmediatamente congelados, para después ser llevados al laboratorio del INP, para su posterior análisis.

De las muestras de aguas colectadas en la misma botella Niskin, se obtuvieron muestras para análisis de fitoplancton, las cuales se colectaron en frascos de $200 \mathrm{ml}$ de capacidad. A cada muestra se agregó 8 a 10 gotas de una solución de Lugo para su conservación (Ferrario et al., 1995). 
Después se procedió a realizar un arrastre superficial con redes de plancton de 200 micras de ojo de malla, para la obtención de organismos del zooplancton (Boltovskoy, E. (1981). El arrastre se lo realizó a una velocidad de la embarcación de dos nudos durante cinco minutos. Luego se procedía a recoger las redes y el plancton atrapado en la red era colectado en frascos de $200 \mathrm{ml}$ de capacidad, al cual se le agregaba entre 8 y 10 $\mathrm{ml}$ de formol neutralizado con tetraborato de sodio (Boltovskoy, E. (1981 y Ferrario et al., 1995).

\section{Fase de laboratorio}

En el laboratorio de química del INP, a las muestras de agua para el análisis químico, se le determinaron los siguientes elementos químicos: nitrito [NO2], nitrato [NO3], fosfato [PO4], silicato [SiO4], y oxígeno disuelto [O2]. Los valores de los nutrientes fueron calculados en base a los criterios de Strickland y Parsons (1972). El oxígeno disuelto fue valorado por el método de Winkler reformado por Carpenter (1965).

En el laboratorio de plancton del INP, se procedió a realizar el análisis cualicuantitativo de fitoplancton, por el método Utermöhl, descrito por Mora et al. (2016), luego de haber sedimentados las muestras durante 24 horas en cámaras de sedimentación de 10cc. El recuento se realizó mediante un microscopio invertido y la identificación de los organismos mediantes claves de libros especializados Björnberg (1981).

En tanto, para la estimación del zooplancton, se aplicó el procedimiento descrito por Frontier (1981) luego de colocar una alícuota (25 ml) en una cámara Dolfus (Equipamientos para analice microscópica), para después identificar las especies presentes, principalmente copépodos. Para el análisis cualitativo de las especies se realizaron siguiendo las claves descritas en los libros de identificación de Boltovskoy E. (1981) y Boltovskoy D. (1999). El recuento de los individuos se lo realizó por medio de un microscopio estereoscópico.

Con los datos, se estimó la equitatividad, riqueza y diversidad de Shannon-Wiener (Martella et al., 2012). A continuación, a los mismos datos, se le realizó la prueba de Kolmogorov-Smirnov (Guillen, 2013). Luego de comprobar el no cumplimiento de los supuestos, se aplicaron análisis no paramétrico, Kruskal-Wallis (Soto, 2013), y la prueba Mann-Whitney para estacionalidad (Angulo et al., 2013). Los valores fueron expresados en diagramas de caja y bigotes (García \& Dulcimar, 2013).

Además se aplicó el coeficiente de Spearman entre las variables abióticas y bióticas, para mostrar el grado de correlación entre variables. Así mismo, para conocer las relaciones entre las variables ambientales $\mathrm{y}$ las especies más frecuentes y/o abundantes, se efectuó un análisis de correspondencia canónica (ACC) (Carles, 2014) mediante el programa CANOCO versión 4.5.

\section{RESULTADOS}

\section{Variables físicas y químicas}

El análisis de varianza simple mostró que TSM, silicato y nitrito registraron variaciones latitudinales y temporales significativas $(\mathrm{P}<0.05$. Las dos primeras variables mostraron los valores más altos en la estación del norte, mientras que la última en las estaciones del sur; así mismo, se observó los valores más altos en la época húmeda (figuras $2 \mathrm{y} 3$ ). Nitrito, fosfato $\mathrm{y}$ oxígeno disuelto no mostraron diferencias significativas $(\mathrm{P}>0.05)$. 

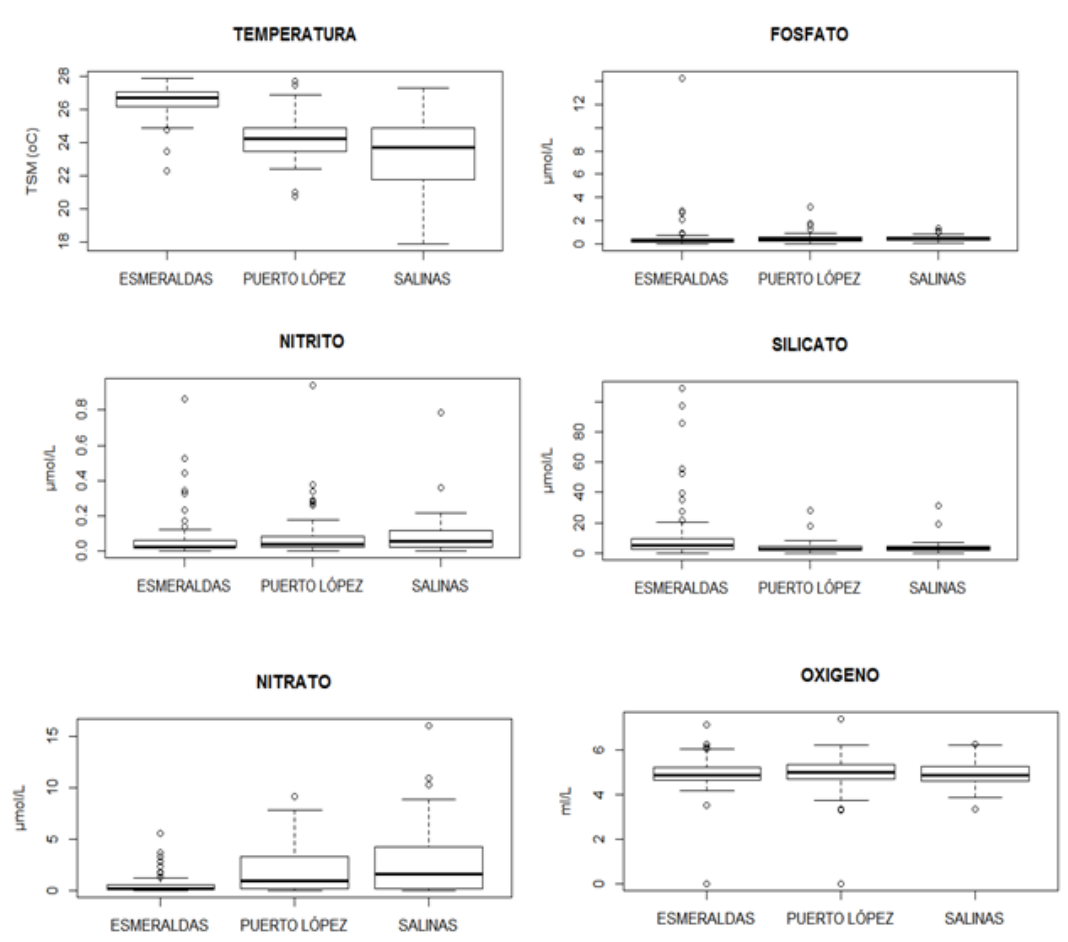

Figura 2. Distribución espacial de temperatura superficial del mar, nitrito, nitrato, fosfato, silicato y oxígeno disuelto en aguas superficiales a diez millas de la costa de Esmeraldas, Puerto López y Salinas.

Figure 2. Spatial distribution of sea surface temperature, nitrite, nitrate, phosphate, silicate and dissolved oxygen in surface waters ten miles off the coast of Esmeraldas, Puerto López and Salinas.
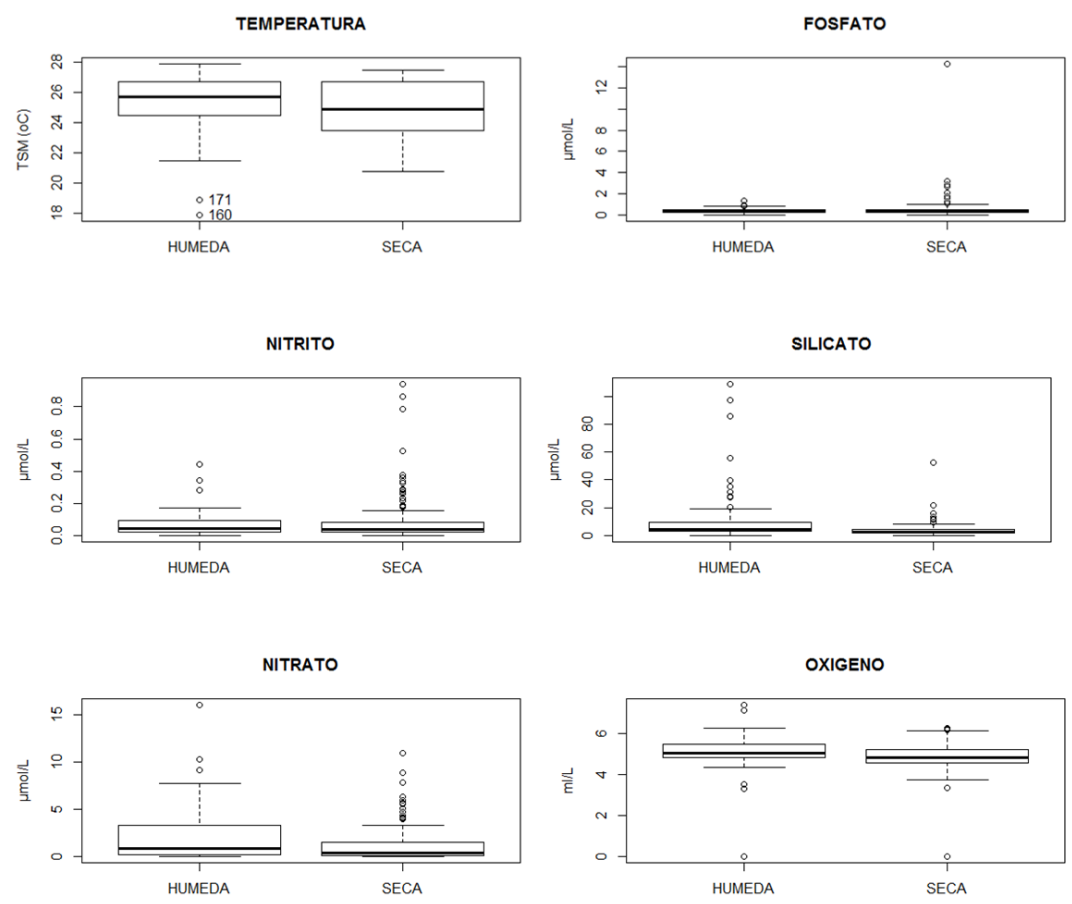

Figura 3. Distribución temporal de temperatura superficial del mar, nitrito, nitrato, fosfato, silicato y oxígeno disuelto en aguas superficiales a diez millas de la costa de Esmeraldas, Puerto López y Salinas.

Figure 3. Temporal distribution of sea surface temperature, nitrite, nitrate, phosphate, silicate and dissolved oxygen in surface waters ten miles off the coast of Esmeraldas, Puerto López and Salinas. 
En Esmeraldas la TSM promedio fluctuó entre 25.7 y $27.5^{\circ} \mathrm{C}$, en Puerto López entre 23.9 y $25.6^{\circ} \mathrm{C}$ y en Salinas entre 22.5 y 24.7 ${ }^{\circ} \mathrm{C}$ (Figura 4).

Los valores de nitrito en Esmeraldas oscilaron entre 0.03 y $0.37 \mu \mathrm{mol} / \mathrm{L}$, detectándose el valor menor en los años 2005, 2008 y 2012, el mayor en el 2004 (Figura 4). En tanto, en Puerto López los valores oscilaron entre 0.03 y $0.21 \mu \mathrm{mol} / \mathrm{L}$, observándose la cifra menor en el 2010 y la mayor en el 2004. Mientras en Salinas se registraron densidades entre 0.07 y $0.21 \mu \mathrm{mol} / \mathrm{L}$, perteneciendo la mínima densidad al 2012 y la máxima al 2005.

Así mismo, el nitrato mostró en Esmeraldas concentraciones que oscilaron entre 0.18 y $1.20 \mu \mathrm{mol} / \mathrm{L}$, en Puerto López valores que fluctuaron entre 0.47 y $4.47 \mu \mathrm{mol} / \mathrm{L}$ y en Salinas densidades entre 0.81 y $5.03 \mu \mathrm{mol} / \mathrm{L}$ (Figura 4).

En tanto el fosfato, registro en Esmeraldas, el valor mínimo $(0.18 \mu \mathrm{mol} / \mathrm{L})$ en el año
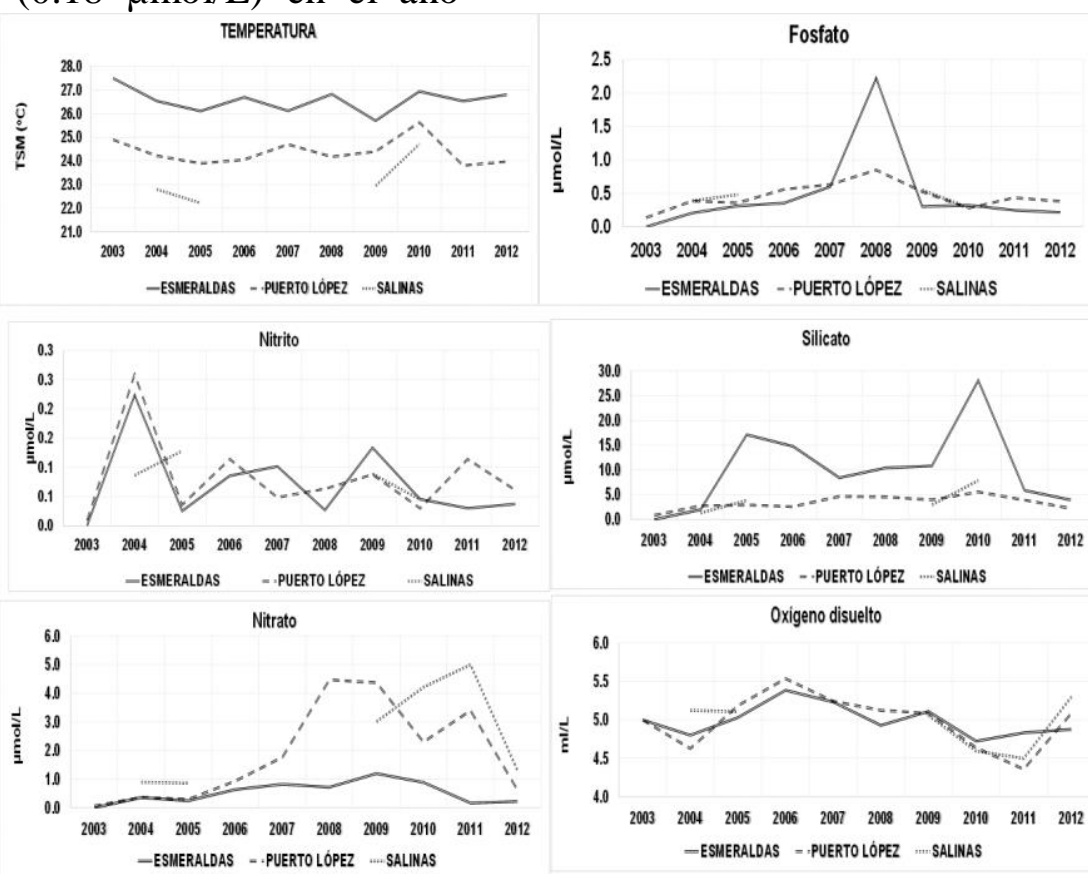

Figura 4. Distribución interanual de temperatura superficial del mar, nitrito, nitrato, fosfato, silicato y oxígeno disuelto en aguas superficiales a diez millas de la costa de Esmeraldas, Puerto López y Salinas.

Figure 4. Interannual distribution of sea surface temperature, nitrite, nitrate, phosphate, silicate and dissolved oxygen in surface waters ten miles off the coast of Esmeraldas, Puerto López and Salinas.
2012 y el máximo $\left(2.28 \mu\right.$ mol.L $\left.{ }^{-1}\right)$ en el 2008. En Puerto López se halló la mínima concentración $(0.31 \mu \mathrm{mol} / \mathrm{L})$ en el 2010 y la máxima $(0.85 \mu \mathrm{mol} / \mathrm{L})$ en el 2008, en Salinas el valor menor $(0.29 \mu \mathrm{mol} / \mathrm{L})$ se mostró en 2010 y el mayor $(0.55 \mu \mathrm{mol} / \mathrm{L})$ en el 2009 (Figura 4).

Por otro lado, el silicato, en Esmeraldas, presentó concentraciones promedio que fluctuaron entre 3.32 y $28.0 \mu \mathrm{mol} / \mathrm{L}$, en cambio en Puerto López, los valores oscilaron entre 2.03 y $5.98 \mu \mathrm{mol} / \mathrm{L}$, mientras que en Salinas, las densidades variaron entre 1.93 y $7.91 \mu \mathrm{mol} / \mathrm{L}$ (Figura $10 \mathrm{~A}$ ) (Figura 4).

En tanto el oxígeno disuelto, mostró valores promedios que fluctuaron entre 4.72 y 5.23 $\mathrm{ml} / \mathrm{L}$ en Esmeraldas; entre 4.48 y $5.24 \mathrm{ml} / \mathrm{L}$ en Puerto López y entre 4.58 y $5.29 \mathrm{ml} / \mathrm{L}$ en Salinas, (Figura 4). La localidad con mayor promedio fue Puerto López y la de menor promedio fue Salinas (Figura 4).

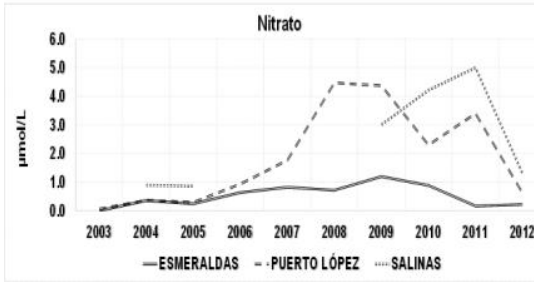




\section{Fitoplancton}

Las densidad y diversidad mostraron diferencias significativas latitudinal $\mathrm{y}$ temporal $(\mathrm{P}<0,05)$. Detectándose mayor abundancia y variedad en la zona norte y en el período seco (figura 5 A-C). En Esmeraldas, la densidad promedio osciló entre 7795 y 33483 cel/L, observándose el valor mínimo en el 2003 y el máximo en el 2009, en tanto la diversidad varió entre 2.09 y 3.51 bits.org, observándose que valores menores a 3.00 bits.org se detectaron del 2007 al 2012, excepto en el 2008 y superiores del 2003 al 2006 (Figura 6 A y B). En Puerto López las concentraciones

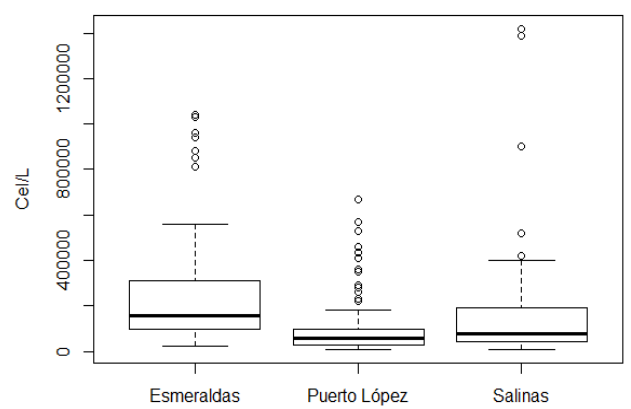

C

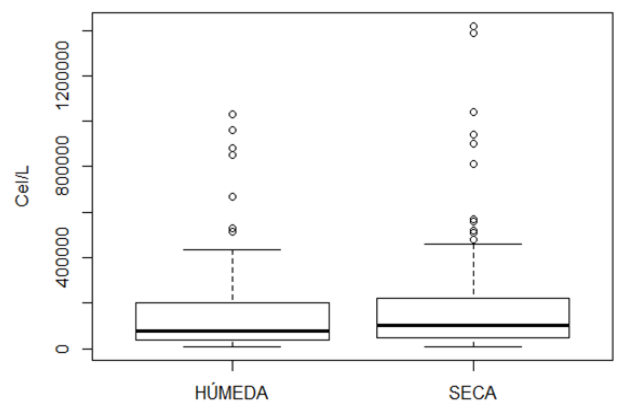

variaron entre 8405 y $29545 \mathrm{cel} / \mathrm{L}$, cifras detectados en el 2006 y el 2011 respectivamente, mientras los valores de la diversidad fluctuaron entre 1.47 y 2.77 bits.org, detectándose cifras menores a 2 bits.org en el 2007 y del 2009 al 2011 y superiores en el resto de años (Figura 6 A y B). En Salinas la abundancias fluctuaron entre 11226 y 44286 cel/L, siendo registrados el valor menor en el 2005 y el mayor en el 2011, así mismo la diversidad varió entre 0,92 y 2,99 bits.org, observándose valores menores a 2 bits.org en el 2009 y el 2010 y mayores en los años 2004, 2005 y 2012 (Figura 6 A y B).

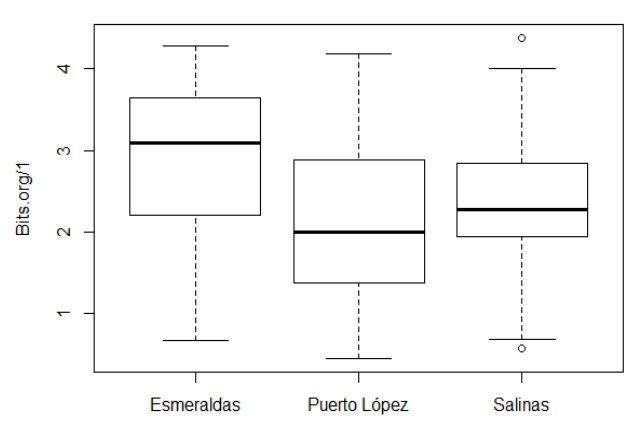

D

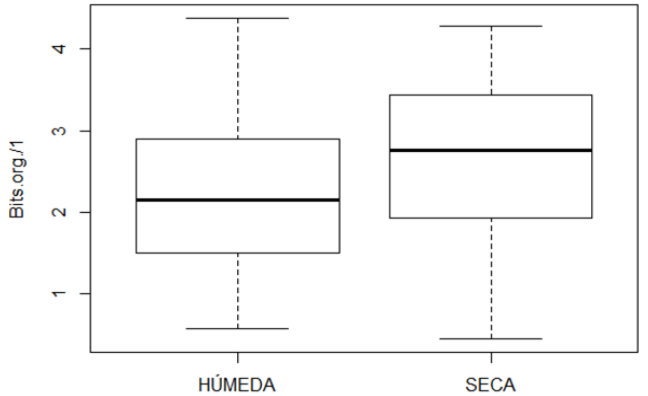

Figura 5. Densidad (A y C) y diversidad (B y D) espacial y temporal de fitoplancton en las aguas superficiales a 10 millas frente a las costas de Esmeraldas, Puerto López y Salinas del 2003 al 2012.

Figure 5. Density (A and C) and diversity (B and D) spatial and temporal phytoplankton in surface waters 10 miles off the coast of Esmeraldas, Puerto López and Salinas from 2003 to 2012. 


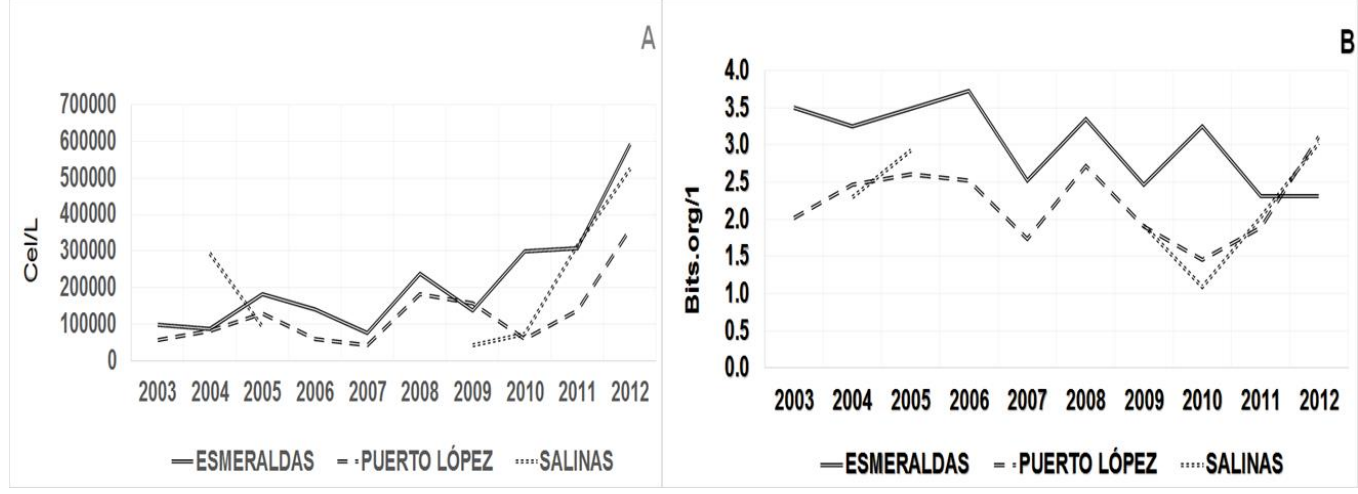

Figura 6. Densidad (A) y diversidad (B) interanual de fitoplancton en las aguas superficiales a 10 millas frente a las costas de Esmeraldas, Puerto López y Salinas del 2003 al 2012.

Figure 6. Density (A) and interannual diversity (B) of phytoplankton in surface waters 10 miles off the coast of Esmeraldas, Puerto López and Salinas from 2003 to 2012.

El análisis taxonómico determinó 11 clases, siendo más frecuentes la Coscinodiscophyceae y Bacillariophycaeae (Figura 7). Ambas clases registraron diferencias significativas $\quad(\mathrm{P}<0.05)$ interanuales siendo diferentes los año 2011 y 2012, respectivamente, así mismo a nivel de sitios, la mayor densidad la registró Salinas, en tanto, la época donde más frecuentaron fue en la seca. Las Cyanophyceae, no mostraron diferencias significativas interanuales. El sitio donde más abundaron fue en Puerto López. Los años en el que mostraron sus valores máximos fueron 2010 y el 2011, a nivel de época fueron más frecuentes en la húmeda. La clase Fragilariophyceae registró diferencia significativa $(\mathrm{P}<0.05)$ entre localidades, detectándose la máxima abundancia en Esmeraldas, en tanto a nivel interanual registró mayor densidad en el 2011. A nivel de época fue abundante en la época húmeda. Las clases Litostomatea, Prymnesiophyceae y Euglenophyceae fueron poco representativas.

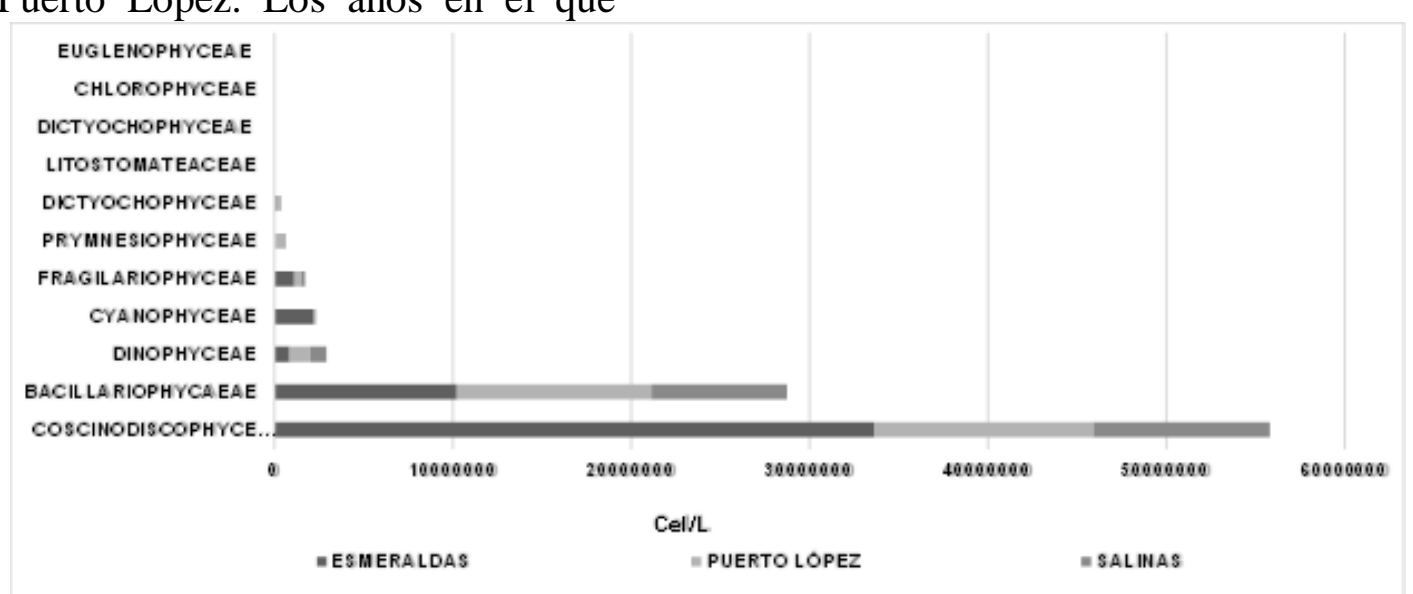

Figura 7. Concentración de las clases del fitoplancton en las estaciones Esmeraldas, Puerto López y Salinas.

Figure 7. Concentration of phytoplankton classes at the Esmeraldas, Puerto López and Salinas stations.

\section{Zooplancton}

La abundancia del zooplancton no mostró diferencias significativas $(\mathrm{p}>0.05)$ latitudinal y temporal (Figuras 8 A y C), pero la diversidad si mostró diferencias significativa a nivel de época $(\mathrm{p}<0.5)$, observándose más abundancia en época seca (Figura 8D). En 
Esmeraldas la densidad promedio osciló entre 27 y 106 org. $\mathrm{m}^{-3}$, detectándose el valor mínimo en el 2008 y el máximo en el 2006, en tanto la diversidad osciló entre 3,07 y 4,02 bits.org-1, correspondiendo el valor mayor al 2008 (Figuras 9 A y B). En Puerto López, la abundancia varió entre 24 y 310 org. $\mathrm{m}^{-3}$, valores detectados en el $2010 \mathrm{y}$ 2012, respectivamente; así mismo, la diversidad fluctuó entre 2,77 y 3,66 bits.org-
1, detectándose cifras menores a 3,00 bits.org ${ }^{-1}$ desde el 2003 al 2005 y en el 2011 y superiores en el resto de años (Figuras 9 A y B). En Salinas las concentraciones fluctuaron entre 26 y 121 org. $\mathrm{m}^{-3}$, registrándose la cantidad menor en el 2010 y la mayor en el 2012, mientras la diversidad varió entre 2,86 y 3,67 bits.org ${ }^{-1}$, siendo el valor menor y único registrado para el año 2005 (Figuras 9 A y B).
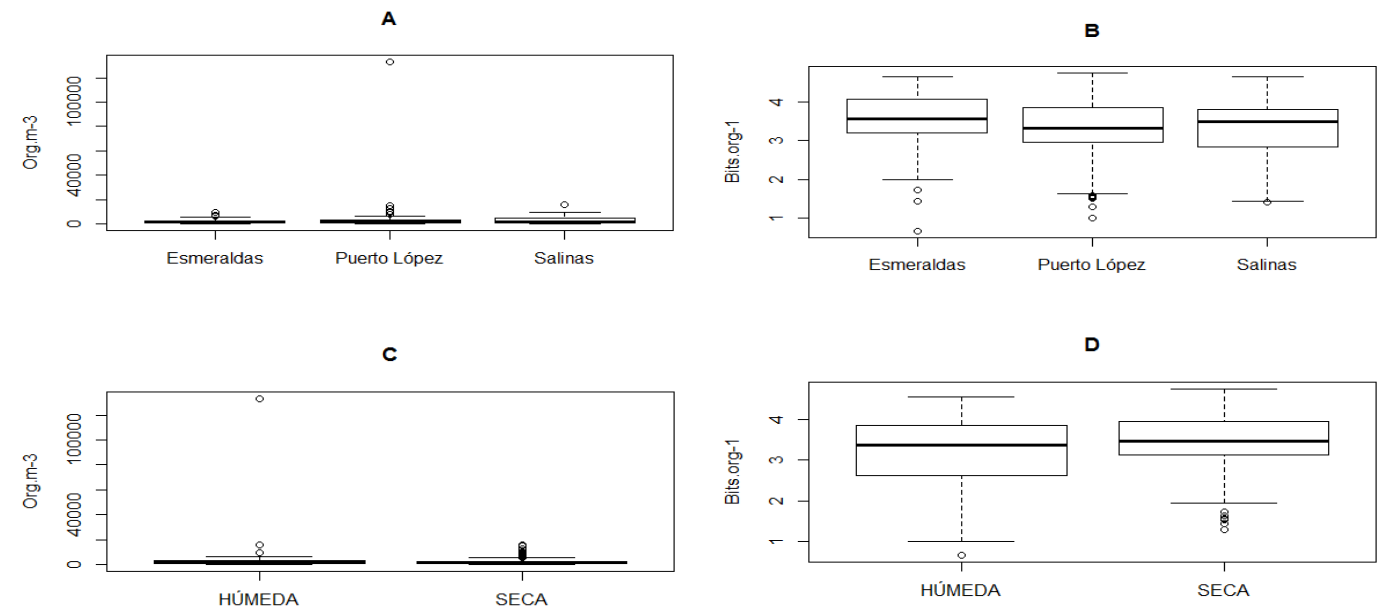

Figura 8. Densidad (A y C) y diversidad (B y D) espacial y temporal de zooplancton en las aguas superficiales a 10 millas frente a las costas de Esmeraldas, Puerto López y Salinas del 2003 al 2012.

Figure 8. Density (A and C) and diversity (B and D) spatial and temporal zooplankton in surface waters 10 miles off the coast of Esmeraldas, Puerto López and Salinas from 2003 to 2012.

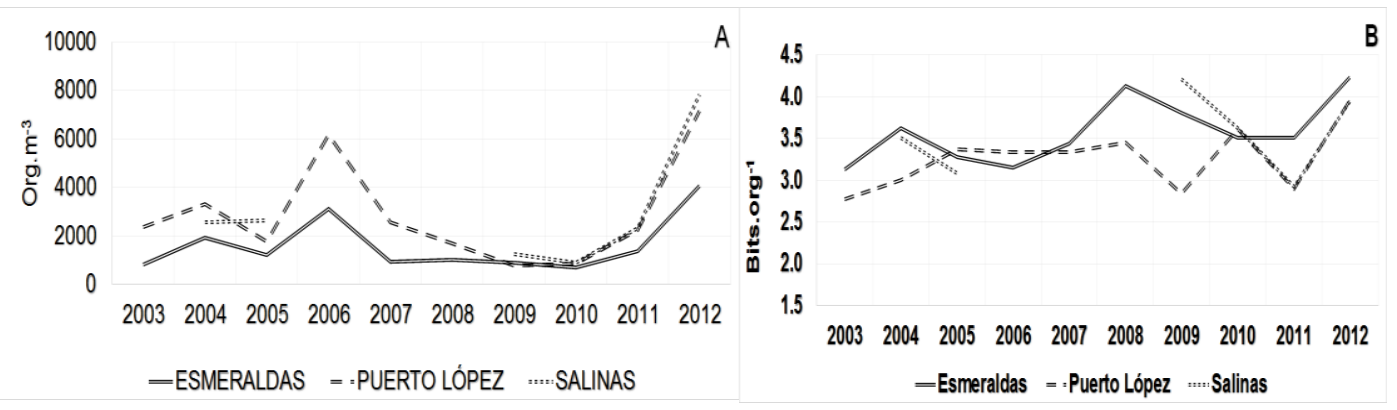

Figura 9. Densidad (A) y diversidad (B) interanual de zooplancton en las aguas superficiales a 10 millas frente a las costas de Esmeraldas, Puerto López y Salinas del 2003 al 2012.

Figure 9. Density (A) and interannual diversity (B) of zooplankton in surface waters 10 miles off the coast of

Esmeraldas, Puerto López and Salinas from 2003 to 2012.

Durante el estudio siete clases fueron las más representativas, siendo Maxillopoda y Malacostraca las de mayor abundancia (figura 10). Predominando en mayor concentración la primera en Salinas y la segunda en Puerto López. Así mismo, se observó que los grupos registraron las densidades más altas en el 2006 y el 2012 y en la época húmeda. 


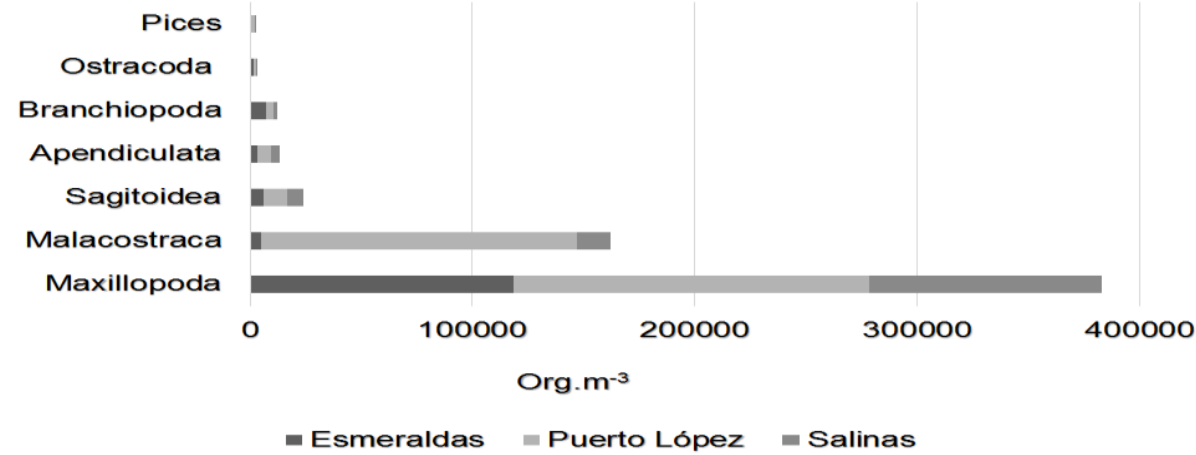

Figura 10. Abundancias de las clases del zooplancton en las estaciones de Esmeraldas, Puerto López y Salinas.

Figure 10. Abundances of the zooplankton classes in the stations of Esmeraldas, Puerto López and Salinas.

\section{Factores abiótico vs bióticos}

El análisis de correlación muestra una correlación positiva del fitoplancton con silicato, oxígeno, nitrato, TSM y zooplancton; negativa con fosfato y nitrato. Así mismo el zooplancton se relacionó negativamente con la TSM (Tabla 1).

Tabla 1. Rango de correlación de Spearman entre variables abióticas y biológicas más representativas.

Table 1. Spearman correlation rank between most representative abiotic and biological variables.

\begin{tabular}{lrrrrrrrr}
\hline & \multicolumn{1}{l}{ FITO } & NO2 & NO3 & O2.L & PO43 & SiO2 & TSM & ZOO \\
\hline \hline FITO & 1.00 & & & & & & & \\
NO2 & $\mathbf{0 . 0 5}$ & 1.00 & & & & & & \\
NO3 & $-\mathbf{0 . 1 1}$ & 0.38 & 1.00 & & & & & \\
O2.L & 0.04 & 0.01 & 0.02 & 1.00 & & & & \\
PO43 & $-\mathbf{0 . 1 4}$ & 0.45 & 0.44 & 0.21 & 1.00 & & & \\
SiO2 & $\mathbf{0 . 1 3}$ & 0.09 & 0.22 & 0.04 & 0.10 & 1.00 & & \\
TSM & $\mathbf{0 . 1 0}$ & -0.26 & $-\mathbf{- 0 . 3 7}$ & -0.12 & $-\mathbf{0 . 3 1}$ & 0.27 & 1.00 & \\
ZOO & 0.06 & 0.12 & -0.01 & $\mathbf{0 . 2 4}$ & 0.09 & -0.22 & $-\mathbf{0 . 2 0}$ & 1.00 \\
\hline
\end{tabular}

\section{Análisis de Correspondencia Canónica (ACC)}

Durante el estudio, el ACC entre especies de fitoplancton y variables ambientales determinó, que la TSM fuera el parámetro de mayor variabilidad y el de menor variabilidad el nitrito. Al primer componente se asoció de modo positivo la TSM y negativamente el oxígeno. Al componente dos se relacionaron en el extremo positivo, silicatos y en el negativo nitrato y fosfato. Al silicato se asoció $C$. closterium; a disco Secchi, $P$. seriata; a nitrato $N$. longissima y $P$. alata, a fosfato $R$. styliformis y a oxigeno $H$. sinensis. El resto de especies se relacionaron de manera débil con las variables (Figura 11a).
El ACC entre el zooplancton y los parámetros ambientales, la TSM, fue el factor de mayor coeficiente al contrario del oxígeno disuelto el menor de todos, siendo inversamente proporcional a $P$. avirrostris. El primer factor, asoció en el extremo negativo al oxígeno disuelto y en el positivo la TSM, observándose que el incremento de la variable estimuló las densidades de Oncaea cleveis, Centropage furcatus, Acrocalanus longicornis, Undinulas vulgaris y Paracacalanus parvus. El segundo componente, correlacionó positivamente al disco Secchi, variable que influyo poco en O. media. La mayor parte de especies se correlacionaron de manera débil con las variables (Figura 11b). 

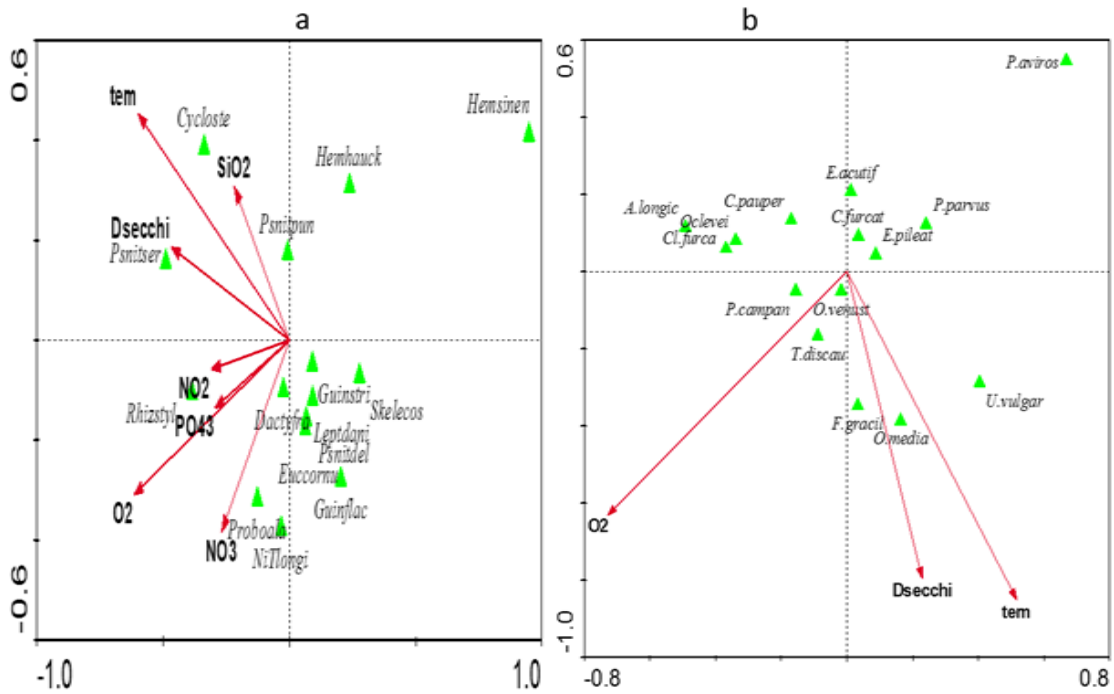

Figura 11. Análisis de Correspondencia Canónica (ACC) de las variables físico-químicas con especies más representativas de fitoplancton (a) y zooplancton (b) durante de 2004 al 2012.

Figure 11. Canonical Correspondence Analysis (CCA) of the physic-chemical variables with most representative species of phytoplankton (a) and zooplankton (b) from 2004 to 2012.

En la tabla 2 se representan las especies indicadoras durante el periodo de estudio, puede distinguirse que no todas la especies son efectivos en la caracterización de una determinada variable en cada localidad, por ejemplo G. striata se muestra como indicadora de nitrito en Esmeraldas, pero no en Puerto López y Salinas. Se detectó que las especies, de acuerdo a su requerimiento físico y químico se mostraron como indicadoras de uno o varios parámetros en una localidad o en varias de ellas

Tabla 2. Especies de fitoplancton y del zooplancton asociadas en mayor grado a las variables ambientales en las tres estaciones durante el periodo de estudio.

Table 2. Phytoplankton and zooplankton species most associated with environmental variables in the three seasons during the study period.

\begin{tabular}{|c|c|c|c|c|c|c|c|c|}
\hline \multicolumn{9}{|c|}{ FITOPLANCTON } \\
\hline \multicolumn{3}{|c|}{ Esmeraldas } & \multicolumn{3}{|c|}{ Puerto López } & \multicolumn{3}{|c|}{ Salinas } \\
\hline Especies & Variable & $\begin{array}{c}\text { Promedio } \\
(\mu \mathrm{m} / \mathrm{L})\end{array}$ & Especies & Variable & $\begin{array}{c}\text { Promedio } \\
(\mu \mathrm{m} / \mathrm{L})\end{array}$ & Especies & Variable & $\begin{array}{c}\text { Promedio } \\
(\mu \mathrm{m} / \mathrm{L})\end{array}$ \\
\hline Guinardia striata & $\mathrm{NO} 2$ & 0.7 & Nitzschia longissima & $\mathrm{NO3}$ & 1.96 & Nitzschia longissima & NO3 & 2.91 \\
\hline Rhyzosolenia styliformis & NO3 & 0.57 & Proboscia alata & & & Proboscia alata & & \\
\hline Dactyliosolen fragilisimus & & & Chaetoceros decipiens & $\mathrm{PO} 3$ & 0.49 & Rhizosolenia styliformis & $\mathrm{PO} 3$ & 0.45 \\
\hline Cylindrotheca closterium & $\mathrm{PO} 3$ & 0.55 & Pseudo-nitzschia pungens & & & Cylindrotheca closterium & $\mathrm{SO} 3$ & 4.08 \\
\hline Chaetoceros decipiens & $\mathrm{SO} 3$ & 11.61 & Nitzschia pacifica & & & Hemiaulus sinensis & $\mathrm{O} 2$ & 4.93 \\
\hline Cylindrotheca closterium & Transp. & & Pseudo-nitzschia pungens & $\mathrm{SO} 3$ & 3.67 & Pseudo-nitzschia seriata & Transp. & \\
\hline Nitzschia longissima & $5.92 \mathrm{~m}$ & & Cylindrotheca closterium & & & & $8.37 \mathrm{~m}$ & \\
\hline Rhizosolenia setigera & T.clina & & Pseudo-nitzschia seriata & Transp. & & & & \\
\hline Bacteriastrum delicatulum & $30 \mathrm{~m}$ & & & $7.13 \mathrm{~m}$ & & & & \\
\hline Pseudo-nitzschia pungens & & & Hemiaulus hauckii Grunow & TSM & & & & \\
\hline \multirow[t]{2}{*}{ Hemiaulus hauckii Grunow } & TSM & & & $21.85^{\circ} \mathrm{C}$ & & & & \\
\hline & $24.75^{\circ} \mathrm{C}$ & & & & & & & \\
\hline \multicolumn{9}{|c|}{ ZOOPLANCTON } \\
\hline \multicolumn{3}{|c|}{ Esmeraldas } & \multicolumn{3}{|c|}{ Puerto López } & \multicolumn{3}{|c|}{ Salinas } \\
\hline Especies & Variable & $\begin{array}{c}\text { Promedio } \\
(\mu \mathrm{m} / \mathrm{L})\end{array}$ & Especies & Variable & $\begin{array}{c}\text { Promedio } \\
(\mu \mathrm{m} / \mathrm{L})\end{array}$ & Especies & Variable & $\begin{array}{c}\text { Promedio } \\
(\mu \mathrm{m} / \mathrm{L})\end{array}$ \\
\hline Evadne tergestina & $\mathrm{O} 2$ & 4.82 & Acrocalanus longicornis & 02 & 4.92 & Oncaea cleveis & $\mathrm{O} 2$ & 4.93 \\
\hline Penilia avirrostris & T.clina & & Oncaea cleveis & & & Clausucalanus furcatus & & \\
\hline Oncaea media & $30 \mathrm{~m}$ & & Clausucalanus furcatus & & & Acrocalanus longicornis & & \\
\hline \multirow[t]{4}{*}{ Calocalanus pavo } & & & Clausucalanus furcatus & T.clina & & Oncaea media & Transp. & \\
\hline & & & Oncaea venusta & $40 \mathrm{~m}$ & & & $8.37 \mathrm{~m}$ & \\
\hline & & & Eucalanus pileatus & & & Undinula vulgaris & TSM & \\
\hline & & & & & & Paracalanus parvus & $20.58^{\circ} \mathrm{C}$ & \\
\hline
\end{tabular}




\section{DISCUSIÓN}

El comportamiento espacial de la temperatura mostró un gradiente de disminución de norte a sur (Figura 2). El gradiente es evidenciado como consecuencia del predominio de aguas cálidas que llegan desde la cuenca de Panamá afectando la zona norte del Pacifico Ecuatoriano, mientras que la zona sur es influenciada por un ramal de la corriente fría de Humboldt (CPPS, 2014).

Estas dos masas de agua determinan que la TSM sea más baja en el verano y más alta en el invierno (Figuras 3); similar tendencia confirmó Belén et al. (2013), que analizó el comportamiento de las condiciones climáticas durante la época húmeda en la costa ecuatoriana entre los períodos de 19752000 y de 1981-2010.

La masa de agua superficial de la estación Esmeraldas, localizada entre los 0 y 10 metros de profundidad, podrían ser similar al Agua Tropical Superficial de Colombia; debido que ambas masas tienen como promedio una TSM de $25.7^{\circ} \mathrm{C}$; también observada en la isla Malpelo (Málikov et al., 2010; Rodríguez-Rubio y Giraldo, 2011).

Se podría considerar a la zona marina de la estación de Esmeraldas, en base a la TSM y la salinidad (Moreno et al., 2008), como una punto donde se mezclan las aguas costeras con aguas oceánicas; y por recibir un constante flujo, en forma de cuña, de agua dulce proveniente del río Esmeraldas (Cucalón, 2002). A diferencia de las estaciones de Puerto López y Salinas, cuyos promedios de TSM son menores, pero de salinidad mayor como zonas marinas, mayormente, influenciadas por aguas oceánicas, según Moreno et al. (2008).

De acuerdo al análisis de correlación, la variabilidad de la TSM influyó en la distribución espacial y temporal del plancton, similar percepción fue observada por Inda-Díaz et al., (2013). Galeano y Arteaga (2010), detectaron valores bajos de correlación entre diatomeas y temperatura, El mismo comportamiento detecto Pulina et al., (2016) en Cyclotella sp., y en Thalassiosira sp., mientras Delgado \& Chang (2015) con la biomasa de fitoplancton. En tanto el comportamiento de zooplancton, coinciden con Giraldo et al. (2014); con Álvarez Silva y Torres-Alvarado (2013) y con Zaafa et al., (2012). Quienes detectaron asociación positiva entre zooplancton con la TSM más elevadas.

Así mismo, se detectó abundancias importante de $T$. nichoides y $S$. costatum, $C$. fususvarfusus, $C$. furca, $C$. triposy $S$. trichoidea en TSM que fluctuó entre 21 y 28 ${ }^{\circ} \mathrm{C}$. Similar a lo observado por Sun el al., 2013 y Vargas et al., 2014, pero en TSM que osciló entre 17.9 y $27.8^{\circ} \mathrm{C}$. Lo que indicaría la capacidad del fitoplancton a sobrevivir a variaciones amplias de temperaturas.

Por otro lado, algunas especies fueron halladas tanto en zonas neríticas como oceánicas, entre estas $S$. costatum y $G$. fláccida, las mismas que han sido calificada como eurytopica (Sun el al., 2013). Lo que sugiere que el plancton del mar ecuatoriano tendría la capacidad de adaptarse a las diferentes masas de aguas (corriente de Humboldt y del Niño) que se presentan, en su debida época.

Además, en la zona de estudio, se dan dos períodos estacionales (invierno y verano), donde los cambios de temperaturas no son bruscos, como en zonas que tienen cuatro períodos estacionales, observándose sucesiones de especies y una termoclina que desaparece en el invierno (Flores et al., 2013). Sin embargo, a pesar de la capacidad de adaptación, pueden ser afectados 
negativamente por el calentamiento de los océanos (Thomas et al., 2012).

Tapia y Naranjo (2012), reportan la presencia de: Thalassiosira subtilis, Chaetoceros curvisetus Ch. eibenii, Rhizosolenia imbricata, Proboscia alata y Planktoniella sol como indicadoras del Frente Ecuatorial, de las cuales solo: $C$. curvisetus, $P$. alata y $R$. imbricata fueron reportadas en este estudio. Sin embargo, no se las detectó en la época en la que coincidió con el estudio (septiembre 2011) de Tapia y Naranjo (2012). No obstante, fueron reportadas en otros años y meses. Por otro lado, si el frente se localiza entre 0 a $3^{\circ} \mathrm{S}$ y las especies propuestas como indicadoras también fueron encontradas en la estación Esmeraldas, lo que manifiesta que las especies de fitoplancton no son indicadoras puntuales de un evento, sino que cumplen varios funciones ecológicas, según su ubicación en el océano y su abundancia, pues los mismos investigadores mencionan que estas especies son indicadoras de masas de aguas oceánicas y de afloramientos.

A igual que la TSM, los nutrientes, mostraron una variabilidad temporal $\mathrm{y}$ espacial. Con respecto al silicato, los resultados indicaron mayor concentración en la zona costera de Esmeraldas, evidentemente, ocasionado por un mayor aporte de las aguas del río Esmeraldas, cuyo recorrido puede llegar hasta 15 millas mar afuera (Cucalón, 2002), siendo la época húmeda la de mayor descarga. Hay que considerar que el punto de muestreo se encontraba a 10 millas náuticas de la desembocadura del río, razón por la cual sería mayor la concentración. Situación diferente la de Puerto López y Salinas donde las concentraciones fueron menores (Figura 4).

Por otro lado, comparando las concentraciones de los rangos de silicatos de este estudio con los reportado por la SETEMAR (2015), en cruceros realizados en Galápago. En este estudio, la concentración es superior con respecto a los datos de la SETEMAR (2015). Pues tal que, el silicato osciló entre $5-20 \mathrm{mg} / \mathrm{L}$, durante la estación lluviosa, seca, el Niño y la Niña, mientras que este estudio lo reportó entre 6.37- $28,0 \mathrm{mg} / \mathrm{L}$. Tendencia similar, para los cruceros del pacifico peruano (1.70$34.57 \mathrm{mg} / \mathrm{L})$, (García et al., 2015).

$\mathrm{Si}$ se compara los valores promedios máximos con los cruceros del pacífico peruano, se observó que fueron mayores (0,0-30,0 mg/L) frente a Perú (Graco et al., 2007), con respecto a esta investigación (2.58-13.45 $\mathrm{mg} / \mathrm{L})$. Estas diferencias, en relación a los cruceros de Ecuador y Colombia, se deben a la ubicación de las estaciones, en este estudio fueron a 10 millas de la costa, mientras que las estaciones de los cruceros fueron en su mayoría oceánicas.

Al estar cerca de la costa reciben mayor carga de sedimento fluvial de los ríos aledaños con alto contenido de silicato, el mismo que se va diluyendo a medida que se adentra al mar. Con respecto a los cruceros peruanos, la mayor concentración de nutrientes están correlacionas con las persistentes y fuertes afloramientos que se producen en el mar peruano (Castillo et al., 2007).

Así mismo, relacionando los datos con el Domo de Costa Rica, se detecta un rango promedio de silicato mayor en la zona costera de Ecuador que la del Domo, como lo evidencia una investigación realizada por Selph et al. (2015). Pues, los investigadores reportaron concentración de silicato entre $2.8-4.2 \mathrm{mg} / \mathrm{L}$ en la zona costeras y en alta mar del Domo de Costa Rica.

En el mismo sentido de la variabilidad espacial y temporal, las concentraciones de 
nitrito y nitrato que fueron más elevadas en Puerto López y Salinas, podrían estar relacionadas a la corriente de Humboldt y al aporte de las aguas del Golfo de Guayaquil. No obstante, al ser mayor la concentración en época húmeda, se sugiere que estos elementos vendrían del aporte de las aguas del rio Guayas. Puesto que, durante el invierno se producen inundaciones en toda la cuenca baja del Guayas y por tanto el arrastre de fertilizantes de los cultivos.

En el informe de la SETEMAR (2015), señalan rangos de nitrato entre $2-6 \mathrm{mg} / \mathrm{L}$, y fosfato de $0.2-2.0 \mathrm{mg} / \mathrm{L}$, durante la estación lluviosa, seca, el Niño y la Niña, mientras en esta investigación se estimaron rangos en 2.01-16.06 mg/L y de 0.63-14.28 mg/L respectivamente. Observándose que los niveles obtenidos este estudio es superior. Incluso son superiora los datos registrados en la zona tropical del Pacífico Oriental Sur durante El Niño y La Niña (nitrato=0.13$0.39 \mathrm{mg} / \mathrm{L} ; \quad$ fosfato=; $0.35-0.44 / \mathrm{L})$ (Dekaezemacker et al., 2013). Y superior a los reportados por Selph et al., (2015) en el Domo de Costa Rica (nitrato $=1.5-2.3 \mathrm{mg} / \mathrm{L}$; fosfato $=0.28 \mathrm{mg} / \mathrm{L}$ ). Al igual que el silicato los promedios de este estudio son inferiores (nitrato $=0.45-2.97 ;$ fosfato $=0.28-1.54 \mathrm{mg} / \mathrm{L}$ ) a Perú (nitrato $=0,0-35,0$; fosfato $=0,2-4,0$ $\mathrm{mg} / \mathrm{L})$ (Graco et al., 2007). Diferencias que tiene una explicación similar en la del silicato.

Comparando los valores promedios de nitrato y fosfato obtenidos frente a la costas del Ecuador, resultaron ser inferiores a los reportados frente a Perú (Graco et al., 2007), pero superiores a los registrado por Selph et al. (2015) para el Domo de Costa Rica.

Así mismo en comparación a un estudio realizado en el sureste de Brasil por Fernández et al. (2015), se pudo ver que el nitrito resultó superior para este estudio, pero nitrato, fosfato y oxigeno resultaron ser menores. Se plantea entonces que las diferencias se deben a la zona de investigación. La concentración de nutrientes es menor en océano abierto pero mayor en zonas próximas a la costa (Paparazzo et al., 2013).

Los nutrientes antes mencionados y reportados para el Golfo de Guayaquil (Prado et al., 2015), sus promedios resultaron mayores a este estudio. Esta diferencia es debido a la alta concentración de los elementos al interior del golfo, puesto que recibe directamente las descargas del rio Guayas.

Las correlaciones positivas entre nutrientes y fitoplancton, es indicio de que existe una continua disponibilidad de nutrientes para el fitoplancton y a la vez alimento continuo para el zooplancton herbívoro, es así, que los nutrientes no son limitantes para el desarrollo del plancton.

En el caso del silicato, investigaciones anteriores indican que para reproducirse el fitoplancton, la concentración de silicato tiene que ser superior a $0.05 \mathrm{mg} / \mathrm{L}$ (Balnova, 2015), en este estudio el valor mínimo fue $0.8 \mathrm{mg} / \mathrm{L}$. Así mismo, con el oxígeno disuelto, estudio muestran que las especies de zooplancton se desarrollan mejor en zona de alta concentración de oxígeno disuelto (Trejo-Albarrán et al., 2015; RodríguezSáenz et al., 2012). Las concentraciones del oxígeno disuelto, en este estudio coinciden con los rangos tolerados por el zooplancton (Figura 4).

La abundancia del fitoplancton durante el estudio, mostraría la constante disponibilidad de alimento para el nivel trófico secundario (consumidores primarios). Observándose que existiría una eficiente cascada trófica de abajo hacia arriba en las zonas de estudio, y que esta podría ser pequeña, ya que las cascadas tróficas 
estudiadas en el mar han demostrados ser débiles (Borr et al., 2005; Terborgh and Estes. 2013).

Sin embargo, la alta productividad $y$ diversidad fitoplantónica causada por la alta disponibilidad de nutrientes, estaría generando cascadas tróficas de mayor magnitud que las indicadas por los autores antes mencionados.

Del análisis de correspondencia canónica de las variables físicas con nutrientes y el plancton, no presentaron una determinada especie que se relacione de manera fuerte con una determinada variable ambiental, de modo que sea considerada como una indicadora de algún tipo de parámetro en particular para las tres localidades (Tabla 2). Como se puede observar, esto se esperaba, ya que las condiciones ambientales en cada estación son diferentes, a pesar de que los parámetros climáticos medidos son los mismos. Esto se debe a la variabilidad de los factores oceanográficos, ejerciendo una fuerte influencia en la distribución, abundancia y diversidad de las especies (Dabrio \& Polo. 2015; Juárez et al., 2014). Además, las especies se adaptan mejor cuando los factores oceanográficos son favorables, debido a la capacidad que tiene cada especie de sobrevivir y proliferar en las diferentes condiciones oceanográficas.

\section{CONCLUSIÓN}

Las condiciones oceanográficas a diez millas de la costa de Ecuador, evidenciaron valores más elevados de la temperatura superficial del mar y de silicato en la estación del norte $\mathrm{y}$ de nitrato en las estaciones del sur y, siendo más abundantes en el periodo húmedo. Nitrito, fósforo y oxígeno disuelto no mostraron diferencias significativas.

El constante flujo de nutrientes, favoreció la productividad planctónica existiendo una buena relación entre los dos primeros niveles tróficos. De modo, que, existiría una cascada trófica dominada por el fitoplancton ejerciendo el control sobre los niveles tróficos superiores. Evidenciado por el incremento de las larvas de crustáceos y copépodos que implicaría un descenso de Bacillariophycaeae, Coscinodiscophyceae y Dinophyceae.

En base al Análisis de Correspondencia Canónica, la altas abundancias de $H$. hauckii y $U$. Vulgaris coincidieron con temperaturas altas; O. media y E. pileatus, incrementaron cuando la termoclina estuvo más profunda; $G$. striata, aumentó en concentraciones elevadas de nitrito; $R$. styliformis y $N$. longissima, abundaron en el momento que el nitrato aumento; $C$. closterium, $C$. decipiens, $R$. styliformis fueron afines al fosfato; $C$. decipiens y $C$. closterium, se relacionaron con el silicato y $P$. avirrostris y $O$. cleveis tendieron a incrementar en mayores densidades de oxígeno disuelto. Se podría considerar a estas especies como posibles indicadores biológicos de los parámetros mencionados.

\section{AGRADECIMIENTO}

Al Instituto Nacional de Pesca, especialmente al departamento de plancton, oceanografía y química de agua por las bases de datos proporcionados $\mathrm{y}$ al Dr. Luis Trocccoli por la orientación, el seguimiento y la supervisión continúa de esta investigación.

\section{REFERENCIAS}

Álvarez-Silva, C., y Torres-Alvarado, M. (2013). Composición y abundancia del zooplancton de la laguna de Coyuca, Guerrero, México. Hidrobiológica 23(2): 241-249. 
Angulo, N., de Szarvas, S. B., Guevara, H., Mathison, Y., González, D., Hadad, E., \& Hernández, A. (2013). Inflammatory markers in obese school children. Vitae, 52.

Ayala, A., Bonilla, H. R., CalderónAguilera, L. E., Perezrul, M. D. H., \& Espinosa, P. C. G. (2016). Proyección de cambios en la temperatura superficial del mar del Golfo de California y efectos sobre la abundancia y distribución de especies arrecifales. Revista Ciencias Marinas y Costeras, 8(1), 29-40.

Balnova. (05 de agosto del 2015). El silicio, un mineral importante para el afloramiento de las diatomeas en piscinas. Recuperado dehttp/:www.uprm.edu/biology/profs/massol /manual/p3-silica.pdf

Belén del Salto, M., Gálvez, H., y Regalado, J. (2013). Análisis del comportamiento climático de los últimos 30 años, en las costas de Esmeraldas, Manta y Puerto Bolívar durante la época húmeda. Acta Oceanográfica del Pacífico, 18 (1).

Björnberg, T. A. (1981). Copépoda. En: Boltovskoy, D. (Ed.), Atlas del zooplancton del Atlántico Sudoccidental y métodos de trabajo con el zooplancton marino INIDEP. Mar del Plata, Argentina. 587 - 679 pp.

Boltovskoy, D. (1999). South Atlantic zooplankton. Leiden, Netherlands: Backhuys.

Boltovskoy, E. (1981). Atlas del Atlántico Sudoccidental y métodos de trabajo con el zooplancton marino. INIDEP. Mar del Plata, Argentina.

Borer, T., Seabloom, E., Shurin, J., Anderson, K., Blanchette, C., Broitman, B., Cooper, S., y Halpern. B. (2005). What determines the strength of a trophic cascade? Ecology, 86(2), 528-537.

Calderón, G., y Lindao, j. (2009). Abundancia del ictioplancton frente a las costas de Esmeraldas, Punta Galera y Puerto López durante el 2008. Boletín Científico y Técnico, 20 (5), 43-60.

Carles, C. M. (2014). Nuevos métodos de análisis multivariante. CMC Editions, Barcelona España.

Carpenter, J. (1965). The Accuracy of the Winkler Method for Dissolved Oxygen Analysis. Limnol Oceanog, 10, pp. 135-140. Castillo, R., Antezana, T., y Ayon, P. (2007). The influence of El Niño 1997-98 on pelagic ostracods in the Humboldt Current Ecosystem off Perú. Hydrobiologia, 585, 29-41.

CPPS. (2014). Estado del Medio Ambiente Marino y Costero del Pacífico Sudeste. Comisión Permanente del Pacífico Sur CPPS. Guayaquil, Ecuador. Serie Estudios Regionales, 4, 244 p.

Cognetti G, Sara M, Magazzú G (2001) Biología marina. Primera edición. Ed. Ariel. Barcelona España. 619 pp.

Cruz, M. (2012). Preferencia y rangos de tolerancia a la temperatura y salinidad de los Pterópodos y Heterópodos frente a la costa ecuatoriana. Acta Oceanográfica del Pacífico, 17(1).

Cruz, M., Tapia, M., y Naranjo, C. (20102011). Especies planctónicas marinas como bioindicadoras de masas de agua frente a la costa ecuatoriana durante el evento el Niño 2009-2010. Acta Oceanográfica del Pacífico, 16(1).

Cucalón E. (2002). Estudio de los Aspectos físicos del estuario de Esmeraldas. Informe final de Petroecuador: 5-14. 
Dabrio, C. J., \& Polo, M. D. (2015). Cambios del nivel del mar. Enseñanza de las Ciencias de la Tierra, 23(2), 171.

Dekaezemacker, J., Bonnet, S., Grosso, O., Moutin, T., Bressac, M., \& Capone, D. G. (2013). Evidence of active dinitrogen fixation in surface waters of the eastern tropical South Pacific during El Niño and La Niña events and evaluation of its potential nutrient controls. Global Biogeochemical Cycles, 27(3), 768-779.

Delgado, E., \& Chang, F. (2015). La comunidad de fitoplancton en la costa peruana, primavera 2005. InfInst Mar Perú, 42(3).

De la Cuadra, T. (2009). Variabilidad estacional e interanual en estaciones a 10 millas de la costa en el periodo 2004-2008. Boletín Científico y Técnico, 20 (5), 1-16.

Dioses, T. (2013). Patrones de distribución y abundancia del jurel Trachurusmurphyi en el Perú. Revista Peruana de Biología, 20(1), 067-074.

\section{EQUIPAMENTOS PARA ANÁLISE} MICROSCÓPICA. (11 de agosto de 2018). CUBA DE DOLFUS. Recuperado de http://www.flemingbrasil.com.br/layout_hpa ge/p_analise_miscroscopica.htm.

Flores, R., Espino, M., Luque, G., \& Quispe, J. (2013). Patrones de variabilidad ambiental en el mar peruano. Revista Peruana de Biología, 20(1), 21-28.

Ferrario, M. E., Sar, E. A., \& Sala, S. E. (1995). Metodología básica para el estudio del fitoplancton con especial referencia a las diatomeas. Manual de métodos ficológicos, $1-23$.

Frontier, S. (1981). Tratamiento de los datos. En: Boltovskoy, D. (Ed). Atlas de
Zooplancton del Atlántico Sudoccidental y métodos de trabajo con el zooplancton marino INIDEP. Mar del Plata, Argentina. 169-188 pp.

Gadea Pérez, M. I. (2012). Variación espacial del fitoplancton en la zona costera de Gandía y su relación con la entrada de nutrientes. Disponible en http://hdl.handle.net/10251/14442.

Galeano, A., y Arteaga, E. (2010). Distribución y abundancia de diatomeas del género pseudo-nitzschia en condición de el niño 2007 sobre la cuenca pacífica colombiana. Boletín de Investigaciones Marinas y Costeras, 39(1).

García-Dulcimar, J. (2013). Distribución vertical y temporal del zooplancton con sistema de filtración por bomba en la ensenada de turpialito, Estado Sucre, Venezuela. Universidad de Oriente. Venezuela.

García, V., Rubio, J., Sánchez, G., Sánchez, S., Orozco, R., Huerto, M., \& Cervantes, C. (2015). Calidad del ambiente marino y costero en la Región Áncash, 2012.InfInst Mar Perú, 42(4).

Giraldo, A., Valencia, B., Acevedo, J., \& Rivera, M. (2014). Fitoplancton y zooplancton en el área marina protegida de Isla Gorgona, Colombia, y su relación con variables oceanográficas en estaciones lluviosa y seca. Rev. Biol. Trop, 62, 117-132.

Guillen, A., Badii, M. H., Abreu, J. L., \& Rodríguez, H. (2013). Modelos Estadísticos Paramétricos y No Paramétricos para dos Muestras. Revista Daena (International Journal of Good Conscience), 8(3).

Graco, M., Ledesma, J., Flores, G., y Girón, M. (2007). Nutrientes, oxígeno y procesos biogeoquímicos en el sistema de surgencias 
de la corriente de Humboldt frente a Perú. Rev, peru, biol, 14(1), 117- 128.

Gualancañay, E., Tapia, M., Naranjo, C., Cruz, M., Villamar, F. (2010-2011). Caracterización biológica de la bahía de Jaramijó en la costa ecuatoriana, 2008. Acta oceanográfica del pacífico, Vol. 16, (1).

Inda-Díaz, E. A., Domínguez-Ojeda, D., Romero-Bañuelos, C. A., Navarro, J. T. N., \& Morales, J. C. (2013). El zooplancton marino de la costa de Nayarit, México. Revista Fuente nueva época Año, 4(14).

Juárez, M., Sánchez, A., \& GonzálezYajimovich, O. (2014). Variabilidad de la productividad biológica marina en el Pacífico nororiental durante el último milenio. Ciencias marinas, 40(4), 211-220.

Luzuriaga, M. (2015). Foraminíferos Planctónicos vivos en condiciones normales del mar ecuatoriano y durante el evento "el niño" 1997- 1998. Acta Oceanográfica del Pacífico Vol. $20 \mathrm{~N}^{\mathrm{o}} 1$.

Málikov, I., Villegas, N., y J. Moreno. (2010). Identificación de masas de agua horizontales y verticales como base para la localización de estaciones de monitoreo océano-atmosférico en la cuenca del pacífico colombiano. Investigación, Biodiversidad y Desarrollo, 29 (1), 68-78.

Martella, M. B., Trumper, E. V., Bellis, L. M., Renison, D., Giordano, P. F., Bazzano, G., \& Gleiser, R. M. (2012). Manual de Ecología. Evaluación de la biodiversidad. Reduca (Biología), 5(1).

Mesas, A., \& Tarifeño, E. (2015). Temperaturas letales superiores para el mejillón, Mytilus galloprovincialis (Lamarck, 1819), en la costa de Chile central. Latinamerican journal of aquatic research, 43(3), 473-483.
Mora, M., Ascón, D., \& Hung, A. (2016). Evaluación y validación de la prueba de PCR para el control y monitoreo de diatomeas del género Pseudo-nitzschia en las bahías de Guaynuna y Salinas. Salud y Tecnología Veterinaria, 3(1), 13.

Moreno, L., Villegas, N., y Málikov, I. (2008). Análisis de la relación entre masas de aire y masas de agua superficiales sobre la Cuenca del Pacífico Colombiano para el establecimiento de estaciones hidrometeorológicas de monitoreo. Bol Cient CIOH, 26, 188-204.

Parsons, T., Y. Maita and C. Lally. 1984. A manual of chemical and biological methods of sea water analysis. Pergamon, Oxford. $189 \mathrm{p}$.

Paparazzo, F. E., Farias, L., Santinelli, N., Alder, V. A., \& Esteves, J. L. (2013). Incorporación de nitrato por fitoplancton en dos ambientes marinos diferentes de la provincia de Chubut (42-46 S, Argentina). Revista de biología marina y oceanografía, 48(3), 591-600.

Prado, M., Troccoli, L., \& Moncayo, E. (2015). Cambios estructurales del microfitoplancton en la zona costera de la provincia el oro-ecuador en temporada seca. Boletín del Instituto Oceanográfico de Venezuela, 54(2).

Pulina, A., Brutemark, A., Suikkanen, S., Padedda, B., Grubisic, L., Satta, C., Caddeo, T., Farina, P., Sechi, N., and Lugliè, L. (2016). Effects of warming on a Mediterranean phytoplankton community. Web Ecol., 16, 89-92.

Rodríguez-Rubio., E., y Giraldo., A. (2011). Características Oceanográficas en la isla Malpelo y su relación con la cuenca oceánica del Pacífico Colombiano. Boletín 
de Investigaciones Marinas y Costeras, 40 (Supl. Esp).

Rodríguez-Sáenz, K., \& Morales-Ramírez, A. (2012). Composición y distribución del mesozooplancton en una zona de afloramiento costero (Bahía Culebra, Costa Rica) durante La Niña 1999 y el 2000. Revista de Biología Tropical, 60, 143-157.

Selph, K. E., Landry, M. R., Taylor, A. G., Gutiérrez-Rodríguez, A., Stukel, M. R., Wokuluk, J., \& Pasulka, A. (2015). Phytoplankton production and taxon-specific growth rates in the Costa Rica Dome. Journal of plankton research, 38(2), 199215.

SETEMAR (2015). Borrador del Estudio de Impacto Ambiental Proyecto para la Recolección y Procesamiento de datos con Sísmica de Reflexión Multicanal en 2D (dentro del área de la reserva marina de Galápagos). Ecoeficiencia, Gestion Ambiental.

Soto, P. L. (2013). Contraste de hipótesis. Comparación de más de dos medias independientes mediante pruebas no paramétricas: Prueba de Kruskal-Wallis. Revista Enfermería del Trabajo, 3(4), 166171.

Strickland, J., y Parsons, T. (1972). A Practical Handbook of Sea Water Analysis. Bull. Fish. Res. Board of Canada, 67.

Sun, C., Wang, Y., Wu, M., Dong, J., Wang, Y., Sun, F., and Zhang, Y. (2013). Seasonal Variation of Water Quality and Phytoplankton Response Patterns in Daya Bay, China. Int. J. Environ. Res. Public Health, 8, 2951-2966.
Tapia, E. (2013). Composición y distribución del fitoplancton durante la prospección sísmica en la costa ecuatoriana, diciembre de 2008. Acta Oceanográfica del Pacífico, 18 (1).

Tapia, M., y Naranjo, C. (2012). Aspectos Oceanográficos del Plancton y su relación con el Frente Ecuatorial, durante septiembre de 2011. Acta Oceanográfica del Pacífico, $17,(1)$

Terborgh, J., \& Estes, J. A. (Eds.). (2013). Trophic cascades: predators, prey, and the changing dynamics of nature. Island Press.

Thomas, M., Kremer, C., Klausmeier, C., y Litchman, E. (2012). A Global Pattern of Thermal Adaptation in Marine Phytoplankton. SCIENCE, 338, Issue 6110, 1085-1088 pp.

Trejo-Albarrán, R., Granados-Ramírez, J. G., \& Gómez-Márquez, J. L. (2014). Variación del cladócero Daphnia laevis Birge, 1879 en el lago Zempoala, Morelos, México. Editor asociado, 25.

Vargas, E. C., Abarca, J. B., \& Artavia, K. B. (2014). Efectos de El Niño y La Niña sobre el comportamiento del microfitoplancton marino y las variables fisicoquímicas durante el 2008 a 2010 en el Golfo de Nicoya, Costa Rica. Revista Ciencias Marinas y Costeras, 6, 115-133.

Zaafa, A., Ettahiri, O., Elkhiati, N., Blahen, M., Berraho, A., Somoue, L., and Elghrib, H. (2012). Variability of spatial and temporal distribution of marine zooplankton communities in relation with environmental parameters in Tangier and M'Diq (Gibraltar strait) regions. J. Mater. Environ. Sci. 3(2) 262-269. 